\title{
Prevalence of human papillomavirus infection, distribution of viral types and risk factors in cervical samples from human immunodeficiency virus-positive women attending three human immunodeficiency virus-acquired immune deficiency syndrome reference centres in northeastern Brazil
}

\author{
Albert Eduardo Silva Martins ${ }^{1,2 /+}$, Norma Lucena-Silva ${ }^{1,2}$, Renan Gomes Garcia ${ }^{1}$, Stefan Welkovic ${ }^{3}$, \\ Aureliana Barboza ${ }^{4}$, Maria Luiza Bezerra Menezes ${ }^{4}$, Magda Maruza ${ }^{5}$, \\ Terezinha Tenório ${ }^{6}$, Ricardo AA Ximenes ${ }^{7}$
}

\begin{abstract}
'Laboratório de Imunogenética, Centro de Pesquisas Aggeu Magalhães-Fiocruz, Recife PE, Brasil ${ }^{2}$ Laboratório de Biologia Molecular, Departamento de Oncologia Pediátrica, Hospital de Ensino, Instituto de Medicina Integral Professor Fernando Figueira, Recife, PE, Brasil ${ }^{3}$ Disciplina de Obstetrícia e Ginecologia, Centro Integrado de Saúde Amaury de Medeiros ${ }^{4}$ Departamento Materno-Infantil, Faculdade de Ciências Médicas, Universidade de Pernambuco, Recife, PE, Brasil ${ }^{5}$ Hospital Correia Picanço, Secretaria de Saúde de Pernambuco, Recife, PE, Brasil ${ }^{6}$ Departamento Materno-Infantil ${ }^{7}$ Departamento de Medicina Tropical, Universidade Federal de Pernambuco, Recife, PE, Brasil
\end{abstract}

Human immunodeficiency virus (HIV)-positive patients have a greater prevalence of coinfection with human papillomavirus $(H P V)$ is of high oncogenic risk. Indeed, the presence of the virus favours intraepithelial squamous cell lesion progression and may induce cancer. The aim of this study was to evaluate the prevalence of HPV infection, distribution of HPV types and risk factors among HIV-positive patients. Cervical samples from $450 \mathrm{HIV}$ positive patients were analysed with regard to oncotic cytology, colposcopy and HPV presence and type by means of polymerase chain reaction and sequencing. The results were analysed by comparing demographic data and data relating to HPV and HIV infection. The prevalence of HPV was 47.5\%. Among the HPV-positive samples, 59\% included viral types of high oncogenic risk. Multivariate analysis showed an association between HPV infection and the presence of cytological alterations $(p=0.003)$, age greater than or equal to 35 years $(p=0.002)$, number of partners greater than three $(p=0.002), C D 4^{+}$lymphocyte count $<200 / \mathrm{mm}^{3}(p=0.041)$ and alcohol abuse $(p=0.004)$. Although high-risk HPV was present in the majority of the lesions studied, the low frequency of HPV 16 (3.3\%), low occurrence of cervical lesions and preserved immunological state in most of the HIV-positive patients were factors that may explain the low occurrence of precancerous cervical lesions in this population.

Key words: HPV prevalence - HPV typing distribution - HIV-HPV coinfection - risk factors - HPV types

Human papillomavirus (HPV) is the main aetiological agent for cervical lesions worldwide (Walboomers et al. 1999) and the persistence of high-risk HPV infection is closely associated with the development of intraepithelial neoplasia and cervical cancer (Naucler et al. 2011).

The distribution of HPV types varies according to the geographical area and risk factors for acquiring the infection (Giuliano et al. 1999, Clifford et al 2005). In some regions of Europe and North America, the prevalence of HPV 16 is approximately $43 \%$, regardless of whether a woman is human immunodeficiency virus

doi: $10.1590 / 0074-0276140070$

Financial support: PDTIS-FIOCRUZ, MS Brasil (322/2005)

AESM was a PhD student supported by FACEPE

(APQ-IBPG-1802-4) and NL-S is the recipient of a postdoctoral

fellowship from CNPq (150572/2011-5).

+ Corresponding author: aesmartins@hotmail.com

Received 25 February 2014

Accepted 20 June 2014
(HIV)-positive or HIV-negative (Hariri et al. 2011, Martín et al. 2011, Garbuglia et al. 2012). However, in other regions, such as in Africa, HPV 39, HPV 52 and HPV 58 are equally prevalent in HIV-positive patients (Macleod et al. 2011, Rahman et al. 2011). Despite regional differences in the distribution of viral types, HPV 16 is highly prevalent in cervical cancer patients in comparison with individuals without cancer, regardless of whether these women also have HIV (Naucler et al. 2011).

In the southern and southeastern regions of Brazil, the overall prevalence of HPV among HIV-positive women ranges from 48-78.8\% (Grinsztejn et al. 2009, Corrêa et al. 2011, Melgaço et al. 2011, Araújo et al. 2012, Luz et al. 2012). In the city of Rio de Janeiro, the types most frequently found have been HPV 16, HPV 53 and HPV 58 (Melgaço et al. 2011), which suggests that there is a greater circulation of non-vaccinal viral types in Brazil. The present study had the objectives of evaluating the prevalence and identifying the risk factors of HPV infection and of describing the distribution of viral types in a cohort of HIV-positive women who were attended at three reference centres for HIV/acquired immune deficiency syndrome (AIDS) in the northeastern region of Brazil. 


\section{PATIENTS, MATERIALS AND METHODS}

Study design - The patients included in this study formed part of a prospective cohort of HIV-positive women who were attended at Correia Picanço Hospital, Clinics Hospital and Integrated Health Centre Amaury de Medeiros (CISAM) between May 2007-August 2011. These three hospitals are reference centres for HIVAIDS. The results related to the prevalence of HPV and the identification of risk factors for infection were obtained at the baseline evaluation of the cohort, whereas the data regarding the evolution of infection were obtained during the monitoring period. The study included 450 adult HIV-positive women who were attended at the gynaecology services of these three hospitals. The inclusion criteria were 18 years or older, a known HIV-positive status and agreement to participate in the study with a signed consent statement. Among these, 219 patients returned to the service at least once for follow-up.

Data-gathering and standardisation of techniques - All the women answered a questionnaire for a clinical-epidaemiological assessment and underwent colposcopy and cytological examination. The colposcopy was performed by a member of the research team and in accordance with the Rome international nomenclature for classifying colposcopic features (SBPTGIC 2003). During the colposcopic examination, cervical scrapings were collected for cytopathological and molecular analyses using cytobrushes and then added to TE solution $(10 \mathrm{mM}$ Tris-HCl, $1 \mathrm{mM}$ EDTA, $\mathrm{pH}$ 7.8). The results from the cytological tests were classified in accordance with the standards in the Brazilian guidelines for uterine cervical cancer screening (INCA 2011). In cases in which atypia were identified by colposcopy, cervical biopsy fragments were sent (preserved in 10\% formol) for histopathological analysis, taking into consideration the criteria described in the literature (Schneider \& Schneider 1998).

The cervical scraping samples were stored at $-20^{\circ} \mathrm{C}$ and subsequently used for molecular analyses, which included investigation of the HPV genome and, in positive cases, molecular typing.

$H P V$ detection - Genomic DNA was extracted from the cervical samples using a proteinase $\mathrm{K}$ protocol. Briefly, $20 \mu \mathrm{L}$ of proteinase $\mathrm{K}(10 \mathrm{mg} / \mathrm{mL})$ was added to $100 \mu \mathrm{L}$ of a cervical cell suspension in TE buffer and incubated at $65^{\circ} \mathrm{C}$ for $16 \mathrm{~h}$. After enzyme inactivation at $94^{\circ} \mathrm{C}$ for $10 \mathrm{~min}$, the DNA was purified with one volume of phenol-chloroform solution. The DNA was recovered by centrifugation at $10,000 \mathrm{~g}$ for $5 \mathrm{~min}$ and washed once with chloroform solution. Following incubation of the DNA solution with 0.7 volumes of isopropanol for $16 \mathrm{~h}$ at $-20^{\circ} \mathrm{C}$, the DNA was recovered by centrifugation and suspended in pure water.

The DNA quality was assessed in terms of its capacity to amplify the human constitutive gene gapdh (glyceraldehyde-3-phosphate dehydrogenase) using the GAPDHF primer (5'GTCTCCACCACCATGGAGAAGGCT) and GAPDHR primer (5' CATGCCAGTGAGCTTCCCGTTCA) and the following conditions: $5 \mathrm{~min}$ at $94^{\circ} \mathrm{C}$, followed by 35 cycles of $1 \mathrm{~min}$ at $94^{\circ} \mathrm{C}, 1 \mathrm{~min}$ at $60^{\circ} \mathrm{C}$ and $1 \mathrm{~min}$ at $72^{\circ} \mathrm{C}$. The samples that were positive for amplification of the gapdh gene were then subjected to polymerase chain reaction (PCR) using the primers MY09 (CGTCCMARRGGAWACTGATC) and MY11 (GCMCAGGGWCATAAYAATGG), which amplify a 450-bp fragment from the L1 region of HPV, as previously described (Manos et al. 1989). The reaction was prepared with $25 \mu \mathrm{M}$ of each primer, $200 \mu \mathrm{M}$ dNTP, 2.8 $\mathrm{mM} \mathrm{MgCl}{ }_{2}$ and one unit of DNA polymerase in $1 \mathrm{x}$ buffer. The amplification conditions consisted of $5 \mathrm{~min}$ at $94^{\circ} \mathrm{C}$, followed by 35 cycles of $1 \mathrm{~min}$ at $94^{\circ} \mathrm{C}, 40 \mathrm{~s}$ at $55^{\circ} \mathrm{C}$ and $45 \mathrm{~s}$ at $72^{\circ} \mathrm{C}$. A final extension of $72^{\circ} \mathrm{C}$ for 10 min was performed. All PCR reagents were purchased from Invitrogen (Carlsbad, USA). The amplified products were viewed under ultraviolet light in $2 \%$ agarose gels in TAE buffer stained with $0.5 \mu \mathrm{g} / \mathrm{mL}$ of ethidium bromide and photographed using a Polaroid GelCam (Minnetonka, USA) camera.

HPV typing - The PCR products that were HPVpositive were subjected to DNA sequencing in both directions, using the same primers as in the amplification stage, to characterise the viral type. This was performed using the BigDye ${ }^{\circledR}$ protocol (Applied Biosystems, USA), as described by the manufacturer, with the ABI 3100 genetic analyser (Applied Biosystems). The chromatograms were first viewed using the Mega 5.0 software (Tamura et al. 2011) to evaluate the quality of the sequence. Samples presenting defined peaks and low background on the chromatogram were subjected to the NCBI BLASTN software (ncbi.nlm.nih.gov) to identify the HPV type.

Statistical analysis - The clinical-epidaemiological and laboratory data were entered into a database using Excel 2007 software. To assess the prevalence of HPV infection, women presenting at least one sample that had been found to be positive by PCR were considered positive. The HPV types were classified according to their phylogenetic characteristics, as previously discussed in the literature (de Villiers et al. 2004). Age was categorised by taking a median of 35 years to enable comparisons with the findings in the literature (Garbuglia et al. 2012). The association with smoking was analysed by considering smokers and former smokers either together or separately in relation to non-smokers. Regarding the variable of alcohol abuse, the term "light drinker" was used to mean women whose alcohol intake over the last three months did not exceed 14 days per month and whose daily dose was limited to one glass of wine or distilled drink (250 $\mathrm{mL}$ ) or one can of beer $(350 \mathrm{~mL})$; women with greater alcohol intake were categorised as "heavy drinkers". Drug users were considered individuals who were using or had used any illegal drug (smoked, sniffed or injected). The cut-off point for $\mathrm{CD}^{+} \mathrm{T}$ lymphocytes in 200 cells $/ \mathrm{mm}^{3}$ was used to indicate immunosuppression in the patients.

Stata 10.0 software (Stata Corp LP, USA) was used for the statistical analysis. In the univariate analysis, the odds ratio (OR) and their respective $95 \%$ confidence intervals (CI) and p-values ( $\chi 2$ test and the likelihood ratio) were estimated. Associations producing a p-value $<0.05$ were considered statistically significant. A pvalue $<0.25$ was used as a criterion for the inclusion of variables in the multivariate analysis; to remain in the model, a p-value $<0.05$ or adjusting the value of another 
variable OR for a value higher than $10 \%$ was utilised. The Mann-Whitney $U$ test was used in the analysis of the medians of continuous variables groups. The kappa (k) statistic was used to measure the agreement between two consecutive analyses in the study.

Ethics - This study was approved by the Research Ethical Committee of the CISAM under the registration 0011.0.250.000-05. All women who agreed to participate in the study signed an informed consent form.

\section{RESULTS}

Identification of risk factors for HPV infection - HPV infection was investigated among 450 HIV-positive women who were attended at three reference centres for HIV-AIDS in the state of Pernambuco (PE). Among these, $214(47.5 \%)$ were coinfected with HPV. A total of 310 women (68.9\%) filled out the research questionnaire completely. The losses are described in Figure.

A univariate analysis of the association between HPV infection and socio-demographic variables, habits, characteristics associated with HPV infection and characteristics associated with HIV infection is shown in Table I. The characteristics of the women coinfected with HPV were found to be similar to those of the HIV-positive women without detectable HPV infection in relation to family income $(p=0.352)$, smoking $(p=0.384)$, drinking $(\mathrm{p}=0.184)$, use of drugs $(\mathrm{p}=0.350)$ and pregnancy at diagnosis $(\mathrm{p}=0.357)$. Conversely, age under 35 years $(p=0.005)$, length of time since HIV infection less than 24 months $(p=0.026)$, number of partners greater than three $(\mathrm{p}=0.028), \mathrm{CD} 4^{+}$count $<200 / \mathrm{mm}^{3}(\mathrm{p}=0.044)$ and a schooling level greater than eight years $(p=0.026)$ were shown to be associated with HPV coinfection.

The HPV-positive patients predominantly presented cervical lesions $(p<0.000)$; however, there was no association between the presence of cervical lesions and the degree of oncogenicity $(\mathrm{p}=0.884)$ (data not shown in Table I). The presence of cervical lesions, although statistically associated with HPV infection, was not included in the multivariate model because it is not considered a risk factor for HPV infection.

In the multivariate analysis, the following factors remained in the final model: age under 35 years $(\mathrm{p}=$ $0.001)$, schooling level $(p=0.04)$, number of partners greater than three $(\mathrm{p}=0.01), \mathrm{CD} 4^{+} \mathrm{T}$ lymphocyte count $<200 / \mathrm{mm}^{3}(\mathrm{p}=0.018)$, light drinking $(\mathrm{p}=0.018)$ and heavy drinking $(\mathrm{p}=0.003)$ (Table II).

In an additional analysis, considering all the cytology specimens evaluated (baseline and subsequent assessments), HPV infection was found in $65.8 \%(54 / 82)$ of the samples with cytological alterations, whereas only $31.8 \%(145 / 521)$ of the samples without cytological alterations were HPV-positive. Of the $54 \mathrm{HPV}$-positive samples with cytological alterations, seven were diagnosed as atypical squamous cells of undetermined significance (ASCUS) (13\%) by the cytological evaluation, two as atypical squamous cells-cannot exclude highgrade squamous intraepithelial lesion (ASC-H) (3.7\%), three with the presence of HPV (5.5\%), 27 as low-grade squamous intraepithelial lesion (LGSIL) (50\%) and 15 as high-grade squamous intraepithelial lesion (HGSIL)
(27.8\%). Of the $28 \mathrm{HPV}$-negative samples with alterations by the oncotic cytological evaluation, 11 had a diagnosis of ASCUS (39.3\%), one had evidence of HPV infection (3.6\%), 12 were diagnosed as LGSIL (42.9\%) and four were diagnosed as HGSIL (14.3\%).

HPV typing - Among the 450 women studied, 214 $(47.5 \%)$ were coinfected with HPV. Of these, $178 \mathrm{had}$ HPV typing performed on at least one occasion. The types found most frequently were HPV $53(14.5 \%)$, HPV 58 (13.5\%), HPV 31 (10.7\%), HPV 6 (9.3\%), HPV $61(8.9 \%)$ and HPV $11(7.5 \%)$, representing $64.4 \%$ of all the cases. The types HPV 16 (3.3\%) and HPV 18 (1.9\%) presented low frequencies.

Among the $54 \mathrm{HPV}$-positive samples with cytological alterations, the viral type was identified in 49 (90.7\%). Of the 39 samples with mild dysplasia (ASCUS, ASC-H, HPV and LGSIL), 21 (54\%) were typed as presenting high-grade HPV, among which HPV 53 was the most frequent type ( 8 samples). Among the women with moderate dysplasia (HGSIL), high-grade HPV was also identified in $53 \%$ of the 15 samples evaluated, among which HPV 58 was the most prevalent type (3/8).

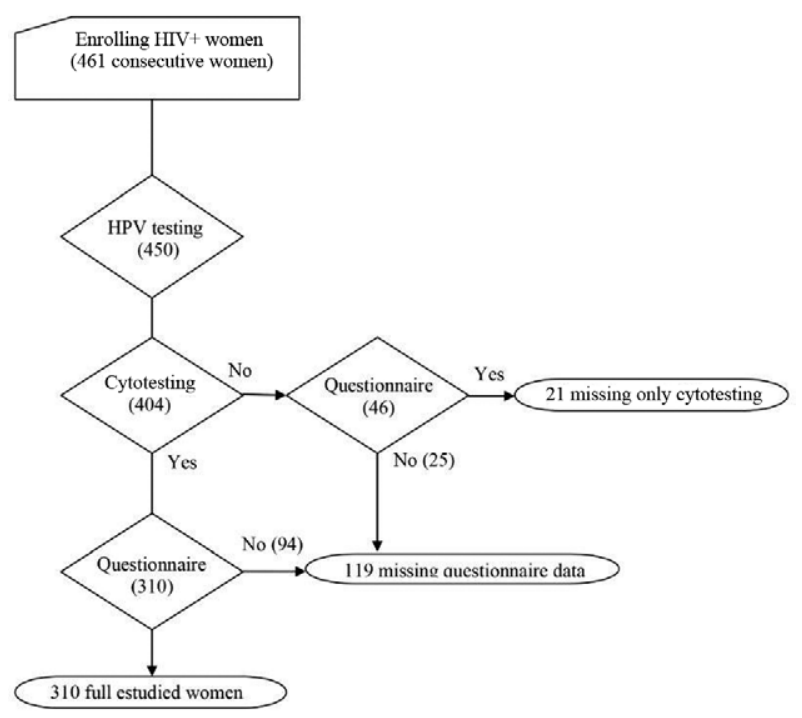

Fluxogram showing the population stratification according the performed testing and missing data. HPV: human papillomavirus.

Biopsies were performed in HPV-positive samples that presented atypia on colposcopy, among which 20 $(40 \%)$ did not present any histological alteration and eight were diagnosed as HPV (16\%), 12 as cervical intraepithelial neoplasia (CIN) I (24\%), nine as CIN II (18\%) and one as CIN III (2\%). The most prevalent HPV types in the biopsies were HPV 16 (in 3 CIN II cases), HPV 31 (in 3 CIN I cases) and HPV 53 (in 1 CIN I and CIN II case). The sample diagnosed with CIN III presented HPV 33.

In contrast, among the seven samples positive for HPV 16 in our study, only one was characterised as HGSIL based on cytology and CIN II from biopsy. Of the six that were negative by cytology, three had an indication for performing a biopsy: two were histologically 
TABLE I

Univariate analysis of the association between human papillomavirus (HPV) infection and socio-demographic variables, habits, characteristics associated with HPV infection and characteristics associated with human immunodeficiency virus (HIV) infection among HIV-positive women attending three reference centres for HIV/acquired immune deficiency syndrome in Recife, Brazil, 2008-2010

\begin{tabular}{|c|c|c|c|c|}
\hline Characteristic & $\begin{array}{c}\text { HPV positive } \\
\text { n (\%) }\end{array}$ & $\begin{array}{c}\text { HPV negative } \\
\text { n }(\%)\end{array}$ & $\begin{array}{c}\text { Odds ratio } \\
(95 \% \mathrm{CI})\end{array}$ & $\mathrm{p}$ \\
\hline \multicolumn{5}{|c|}{ Socio-demographic } \\
\hline \multicolumn{5}{|l|}{ Age (median: 34 years) } \\
\hline$\geq 35$ & $48(36.92)$ & $104(52.79)$ & $0.52(0.33-0.82)$ & 0.005 \\
\hline$<35$ & $82(63.08)$ & $93(47.21)$ & 1.00 & - \\
\hline \multicolumn{5}{|l|}{ Illiteracy } \\
\hline No & $19(14.29)$ & $24(11.76)$ & $1.23(0.64-2.35)$ & 0.422 \\
\hline Yes & $114(85.71)$ & $178(87.25)$ & 1.00 & - \\
\hline \multicolumn{5}{|l|}{ Schooling (years) } \\
\hline$>8$ & $54(40.60)$ & $58(28.86)$ & $1.68(1.06-2.67)$ & 0.026 \\
\hline$\leq 8$ & $79(59.40)$ & $143(71.14)$ & 1.00 & - \\
\hline \multicolumn{5}{|l|}{ Income (minimum wage) } \\
\hline$<1$ & $38(32.76)$ & $49(27.68)$ & $1.27(0.76-2.11)$ & 0.352 \\
\hline$\geq 1$ & $78(67.24)$ & $128(72.32)$ & 1.00 & - \\
\hline \multicolumn{5}{|c|}{ Habits } \\
\hline \multicolumn{5}{|l|}{ Smoking } \\
\hline Smokers & $29(24.58)$ & $31(17.92)$ & $1.50(0.83-2.74)$ & 0.177 \\
\hline Former smokers & $27(22.88)$ & $42(24.28)$ & $1.03(0.58-1.84)$ & 0.902 \\
\hline Non-smokers & $62(52.54)$ & $100(57.80)$ & 1.00 & - \\
\hline \multicolumn{5}{|l|}{ Alcohol intake } \\
\hline Heavy drinker & $10(7.75)$ & $24(12.12)$ & $0.50(0.22-1.14)$ & 0.102 \\
\hline Light drinker & $66(51.16)$ & $110(55.56)$ & $0.72(0.45-1.16)$ & 0.184 \\
\hline Abstainer & $53(41.09)$ & $64(32.32)$ & 1.00 & - \\
\hline \multicolumn{5}{|l|}{ Smoked drug use } \\
\hline Yes & $22(16.92)$ & $26(13.07)$ & $1.35(0.73-2.51)$ & 0.333 \\
\hline No & $108(83.08)$ & $173(86.93)$ & 1.00 & - \\
\hline \multicolumn{5}{|l|}{ Sniffed drug use } \\
\hline Yes & 15 (11.72) & $20(10.10)$ & $1.18(0.58-2.40)$ & 0.645 \\
\hline No & $113(88.28)$ & $178(89.90)$ & 1.00 & - \\
\hline \multicolumn{5}{|l|}{ Drug use } \\
\hline Yes & $24(19.51)$ & $30(15.46)$ & $1.32(0.73-2.39)$ & 0.350 \\
\hline No & 99 (80.49) & $164(84.54)$ & 1.00 & - \\
\hline \multicolumn{5}{|c|}{ HPV related } \\
\hline \multicolumn{5}{|c|}{ Number of sexual partners } \\
\hline$\geq 4$ & $56(45.90)$ & $64(33.51)$ & $1.68(1.05-2.68)$ & 0.028 \\
\hline $1-3$ & $66(54.10)$ & $127(66.49)$ & 1.00 & - \\
\hline \multicolumn{5}{|c|}{ Pregnancy on HPV diagnosis } \\
\hline Yes & $24(18.75)$ & $29(14.87)$ & $1.32(0.72-2.39)$ & 0.357 \\
\hline No & $104(81.25)$ & $166(85.13)$ & 1.00 & - \\
\hline \multicolumn{5}{|l|}{ Papanicolaou testing } \\
\hline No & $27(21.09)$ & $44(22.22)$ & $0.93(054-1.60)$ & 0.810 \\
\hline Yes & $101(78.91)$ & $154(77.78)$ & - & - \\
\hline \multicolumn{5}{|c|}{ Frequency of Papanicolaou testing } \\
\hline Other & $39(32.50)$ & $52(29.05)$ & $1.18(0.71-1.94)$ & 0.525 \\
\hline At least once a year & $81(67.50)$ & $127(70.95)$ & - & - \\
\hline
\end{tabular}




\begin{tabular}{|c|c|c|c|c|}
\hline Characteristic & $\begin{array}{c}\text { HPV positive } \\
\text { n }(\%)\end{array}$ & $\begin{array}{c}\text { HPV negative } \\
\text { n (\%) }\end{array}$ & $\begin{array}{c}\text { Odds ratio } \\
(95 \% \mathrm{CI})\end{array}$ & $\mathrm{p}$ \\
\hline \multicolumn{5}{|c|}{ Presence of cytological alterations } \\
\hline Yes & $31(25.62)$ & $18(9.52)$ & $3.27(1.73-6.17)$ & 0.000 \\
\hline No & $90(74.38)$ & $171(90.48)$ & 1.00 & - \\
\hline \multicolumn{5}{|c|}{ HIV related } \\
\hline \multicolumn{5}{|c|}{$\mathrm{CD}^{+}{ }^{+} \mathrm{T}$ lymphocyte count ${ }^{a}$} \\
\hline$<200 / \mathrm{mm}^{3}$ & $23(20.54)$ & $18(10.40)$ & $2.21(1.13-4.31)$ & 0.044 \\
\hline$\geq 200 / \mathrm{mm}^{3}$ & $89(79.46)$ & $154(89.02)$ & 1.00 & \\
\hline \multicolumn{5}{|c|}{ Length of time since HIV diagnosis (months) } \\
\hline$\geq 24$ & $69(55.20)$ & $133(67.51)$ & $0.59(0.37-0.94)$ & 0.026 \\
\hline$<24$ & $56(44.80)$ & $64(32.49)$ & - & - \\
\hline \multicolumn{5}{|c|}{ Use of anti-retroviral therapy } \\
\hline No & $33(30.28)$ & $41(22.53)$ & $1.49(0.87-2.55)$ & 0.142 \\
\hline Yes & $76(69.72)$ & $141(77.47)$ & 1.00 & - \\
\hline
\end{tabular}

$a$ : on the $\mathrm{CD}^{+} \mathrm{T}$ cells count the result closest to the date of the interview was considered. CI: confidence interval.

characterised as CIN II and one was negative. The three women who presented CIN II based on histological evaluations had $\mathrm{CD}^{+} \mathrm{T}$ lymphocyte counts greater than $200 / \mathrm{mm}^{3}$. Taking into account the immunological state, the distribution of high and low-risk HPV among the immunosuppressed women with $\mathrm{CD}^{+} \mathrm{T}$ lymphocytes $<$ $200 / \mathrm{mm}^{3}$ did not differ from the distribution among the women whose immunological state had been preserved, i.e., with $\mathrm{CD}^{+} \mathrm{T}$ lymphocytes $\geq 200 / \mathrm{mm}^{3}(\mathrm{p}=0.316)$.

Evolution of HPV infection - Among the HIV-positive women who were followed-up clinically, the molecular diagnosis of HPV infection was made for two or more consecutive cervical samples in the cases of 196 women, $86(43.8 \%)$ of whom were negative for HPV on both occasions (Table III). Of the 76 women who were positive for HPV on the first occasion, 50 of them were negative for the other samples, showing a regression rate of $65.8 \%$. Among the 120 women who were negative for HPV on the first occasion, $86(71.7 \%)$ of them remained negative and 34 (28.3\%) became positive. The concordance regarding HPV detection between the first and last samples was considered to be moderate $(\mathrm{k}=0.571)$, in accordance with the interpretation suggested by Landis and Koch (1977).

The persistence of HPV infection was observed in 26 women (13.4\%) and it was possible to perform typing on all samples from 23 of them. Six women (26.1\%) showed the same viral type and 17 (74\%) presented the virus with the same degree of oncogenicity but with a different viral type.

\section{DISCUSSION}

In this study performed in HIV-positive women treated in three centres for HIV-AIDS in PE, the prevalence of HPV infection was $46.5 \%$ and the most frequent viral types were HPV 53, HPV 58, HPV 31, HPV 6, HPV 61 and HPV 11. HPV infection was associated with age less than 35 years, time elapsed since the diagnosis of HIV infection less than 24 months, number of partners higher than three, $\mathrm{CD}^{+}$count $<200 / \mathrm{mm}^{3}$ and more than eight years of schooling. Regarding the evolution of HPV infection, a regression rate of $65.8 \%$ was observed, in contrast to the rate of progression of $28.3 \%$.

\section{TABLE II}

Multivariate analysis of the association between human papillomavirus (HPV) infection and socio-demographic variables, habits, characteristics associated with HPV infection and characteristics associated with human immunodeficiency virus (HIV) infection among HIV-positive women attending three reference centres for HIV/acquired immune deficiency syndrome in Recife, Brazil, 2008-2010

\begin{tabular}{lccc}
\hline HPV infection & Odds ratio & $95 \% \mathrm{CI}$ & $\mathrm{p}$ \\
\hline $\begin{array}{l}\text { Age (years) } \\
\quad \geq 35\end{array}$ & 0.35 & $0.19-0.64$ & 0.001 \\
$\quad<35$ & 1.00 & - & - \\
$\quad$ Schooling (years) & & & \\
$\quad>8$ & 1.93 & $1.03-3.63$ & 0,040 \\
$\quad \leq 8$ & 1.00 & - & - \\
Number of sexual partners & & & \\
$\quad \geq 4$ & 2.30 & $1.22-4.33$ & 0.010 \\
$\quad 1-3$ & 1.00 & - & - \\
CD4+ T lymphocyte count & & & \\
$\quad<200 /$ mm $^{3}$ & 2.72 & $1.19-6.23$ & 0.018 \\
$\quad \geq 200 /$ mm $^{3}$ & 1.00 & - & - \\
Alcohol intake & & & \\
$\quad$ Light drinker & 0.46 & $0.24-0.87$ & 0.018 \\
$\quad$ Heavy drinker & 0.12 & $0.03-0.48$ & 0.003 \\
$\quad$ Abstainer & 1.00 & - & - \\
\hline
\end{tabular}

CI: confidence interval. 


\section{TABLE III}

Persistence of cervical human papillomavirus (HPV) infection in human immunodeficiency virus (HIV)-positive women attending three reference centres for HIV/acquired immune deficiency syndrome in Recife, Brazil, 2008-2010

\begin{tabular}{lcccc}
\hline & \multicolumn{2}{c}{ Last examination } & \multicolumn{2}{c}{ Agreement } \\
\hline First examination & Positive & Negative & Expected & Kappa \\
\hline Positive & 26 & 50 & 0.571 & 0.061 \\
Negative & 34 & 86 & - & - \\
Total & 60 & 136 & - & - \\
\hline
\end{tabular}

Frequency of HPV in cervical infections in HIV-positive women - The prevalence of coinfection with HPV (47.5\%) among HIV-positive women in PE was similar to what has been reported in North America and some European countries, but was lower than that found in populations in southern and southeastern Brazil $(65 \%)$ (Table IV) (Entiauspe et al. 2010, Melgaço et al. 2011, Araújo et al. 2012). In this regard, the influence of the technique used for diagnosing HPV infection needs to be taken into consideration. A Spanish study showed that the prevalence of HPV coinfection among 93 women with HIV-1 infection and normal oncotic cytology was $41 \%$ using the Hybrid Capture II (HC II) method for detecting HPV, but was $63 \%$ using PCR with 16 typespecific primers (Videla et al. 2009). PCR with degenerate MY9/MY11 primers was used in our study and it is possible that the low prevalence of infection encountered was due to the lower sensitivity of this method in relation to methods such as nested PCR or PCR followed by hybridisation, which were used in other groups of patients (Table IV). In the city of Rio de Janeiro, in southeastern Brazil, one study using PCR-restriction fragment length polymorphism (RFLP) methodology and another using the HC assay for HPV typing showed the same HPV 16 prevalence, but diverged with regard to the distribution of the frequency of non-HPV 16 viral types (Grinstejen et al. 2009, Melgaço et al. 2011). The prevalence will also be influenced by the patient selection criteria, i.e., whether they are recruited at referral services for HIV patients or at cancer treatment or gynaecological treatment centres (Naucler et al. 2011).

The HIV-positive women were more susceptible to infection by high-risk HPV types that are known to be less prevalent, such as HPV $53(14.4 \%)$ and HPV 58 (13.4\%), than to types HPV 16 (3.3\%) and HPV $18(1.9 \%)$. HPV 16 is the type found most frequently in HIV-negative women in PE in association with the presence of CIN (Brandão et al. 2009, Baldez et al. 2012). Although a greater prevalence of types HPV 39, 52, 53, 56, 58 and 68 than of HPV 16 has been found among HIV-positive women in previous studies, the HPV 16 infection rate was higher than what was found in the present study (Luque et al. 2006, Grinstejen et al. 2009, Macleod et al. 2011, Rahman et al. 2011, Garbuglia et al. 2012). In southeastern Brazil, HIV-positive women present a notably higher frequency of infection with HPV $16(\sim 20 \%)$ (Grinstejen et al. 2009, Melgaço et al. 2011). HPV 16 was also reported to be of high prevalence in HIV-negative women in southeastern of Brazil, suggesting that the frequencies of viral types may also be related to the geographical distribution of the viral types, independent of HIV status (Nicol et al. 2013). However, we cannot rule out the possibility that the low frequencies of HPV 16 and HPV 18 infection in our study may have been related to the impossibility of determining the viral type in 50 of our samples. The sequencing chromatograms for these samples suggested that cervical infection due to more than one type of HPV was present and this was also confirmed by the banding pattern obtained through the PCR-RFLP protocol (data not shown). However, even considering the possibility that these 50 samples with multiple infections might have included HPV 16, the frequency of this type would still be low.

Risk factors for HPV infection - The relationship between the presence of HPV and cervical oncotic cytological alterations with the presence of CIN has been recognised in several studies (Macleod et al. 2011, Martín et al. 2011, Melgaço et al. 2011, Rahman et al. 2011). However, there is some controversy regarding the causal relationship between epithelial alterations and HPV infection, i.e., between whether epithelial lesions are risk factors for HPV infection or whether they are a consequence of HPV infection. A cohort study among HIV-positive and HIV-negative sex workers showed that chronic infections with a high potential for epithelial damage, such as due to Neisseria gonorrhoeae and Chlamydia, are associated with the acquisition of high-risk HPV, but not with bacterial infections that produce less epithelial damage (Veldhuijzen et al. 2011). Other authors have reported that an association between HPV infection and bacterial infections and Trichomonas (Rodriguez-Cerdeira et al. 2012) may occur regardless of any presence of cytological alterations (Watts et al. 2005), thus acting as co-factors for the development of CIN II (Bhatla et al. 2013). Chronic vaginal infections caused by anaerobic bacteria act as co-factors for the appearance of CIN, independent of HPV infection, through the mechanism of the loss of the natural barrier of lactobacillus, with alterations in the vaginal $\mathrm{pH}$ and the production of DNA adducts (Gillet et al. 2012). The lack of information on associated bacterial infections and the small number of women with severe cytological alterations did not allow a more detailed assessment on the association between HPV infection and the presence of cytological alterations. Within this context, we considered that a tissue lesion would facilitate the access and establishment of HPV in the cervical basal layer, but would not be directly related to a greater chance of exposure and that the virus might be eliminated with resolution of the lesion through an appropriate immunological response. However, the persistence of active viral infection might lead to a progressive worsening of the tissue lesion, thus suggesting that the cytological lesion might be the cause and consequence of HPV infection. Another important 
TABLE IV

Comparison between reported prevalence of human papillomavirus (HPV) infection and methods used for detection of the HPV genome in different populations

\begin{tabular}{|c|c|c|c|c|}
\hline Reference & $\begin{array}{c}\text { State } \\
\text { (country) }\end{array}$ & HPV & $\begin{array}{c}\text { Prevalence } \\
(\%)\end{array}$ & Method \\
\hline This paper & PE (Brazil) & $\mathrm{HIV}+(211 / 464)$ & 47.5 & PCR + sequencing \\
\hline Hariri et al. (2011) & USA & HIV+ (1764/4150 ) & 42.5 & PCR + hybridisation \\
\hline Martín et al. (2011) & Spain & HIV- (1062/2461) & 43.2 & PCR + hybridisation \\
\hline Garbuglia et al. (2012) & Italy & $\mathrm{HIV}+(244 / 553)$ & 44.1 & RFLP \\
\hline Grinsztejn et al. (2009) & RJ (Brazil) & HIV+ (306/634) & 48 & $\mathrm{HC} \mathrm{II}$ \\
\hline Luz et al. (2012) & RJ (Brazil) & HIV+ (324/703) & 48.9 & $\mathrm{HC} \mathrm{II}$ \\
\hline Rahman et al. (2011) & Kenya (Africa) & $\mathrm{HIV}+(487 / 240)$ & 49.3 & Chip assay \\
\hline Luque et al. (2006) & NY (USA) & HIV+ (105/202) & 52 & PCR + hybridisation \\
\hline Entiauspe et al. (2010) & RS (Brazil) & HIV- $(35 / 60)$ & 58.3 & Nested PCR/specific \\
\hline Melgaço et al. (2011) & RJ (Brazil) & $\mathrm{HIV}+(84 / 140)$ & 60 & RFLP \\
\hline Entiauspe et al. (2010) & RS (Brazil) & $\mathrm{HIV}+(30 / 38)$ & 66 & Nested PCR/specific \\
\hline Araújo et al. (2012) & MG (Brazil) & $\mathrm{HIV}+(237 / 348)$ & 68 & Nested PCR/specific \\
\hline Levi et al. (2002) & SP (Brazil) & $\mathrm{HIV}+(204 / 208)$ & 98 & SFP-PCR/LiPA \\
\hline
\end{tabular}

HC: Hybrid Capture assay; HIV: human immunodeficiency virus; LiPA: Line Probe assay; MG: Minas Gerais; NY: New York; PCR: polymerase chain reaction; PE: Pernambuco; RFLP: restriction fragment length polymorphism; RJ: Rio de Janeiro; RS: Rio Grande do Sul; SFP: short PCR fragment; SP: São Paulo; -: negative; +: positive.

point to be considered is that HIV infection might itself independently increase the risk of cytological alterations and HPV infection (Yamada et al. 2008).

The gradual decrease in the occurrence of HPV infection in women over the age of 35 years $(p=0.001)$ corroborates the data in the literature (Grinsztejn et al. 2009, Melgaço et al. 2011, Garbuglia et al. 2012) and may be explained by the decreasing number of sexual partners and acquired immunity against infections (Confortini et al. 2010).

The number of partners was also associated with HPV infection among the women studied $(\mathrm{p}=0.009)$. The association between the number of partners and the occurrence of HPV infection has been reported in both HIV-negative women (Burk et al. 1996, Bicca et al. 2013) and HIV-positive women (Grinsztejn et al. 2009) and can be explained by a greater exposure to sexually transmitted diseases (Hariri et al. 2011).

Although a length of time since being diagnosed with HIV of less than 24 months did not remain in the multivariate model, a study conducted in the city of Rio de Janeiro among individuals with HIV diagnosed less than four years previously showed an association with HPV infection $(\mathrm{p}<0.008)$ (Melgaço et al. 2011).

In general, treatment with antiretrovirals is started when the levels of $\mathrm{CD}^{+} \mathrm{T}$ lymphocytes are lower than $350 / \mathrm{mm}^{3}$; thus, it is possible that HIV-positive patients may present a certain degree of immunity impairment after becoming infected, but before the start of treatment, increasing their susceptibility to infection (Palefsky 2006). The women with $\mathrm{CD}^{+} \mathrm{T}$ lymphocyte counts less than 200 cells $/ \mathrm{mm}^{3}$, which characterises immunosuppression, presented an almost three times greater chance of acquiring HPV infection $(p=0.016)$, thus cor- roborating other findings in the literature (Grinsztejn et al. 2009, Melgaço et al. 2011, Garbuglia et al. 2012).

The association of heavy drinking $(p=0.102)$ or light drinking $(p=0.184)$ with cervical infection due to HPV was observed with a p-value greater than 0.05 in the univariate analysis, but remained in the final model of the multivariate analysis $(p=0.003$ and $p=0.018$, respectively). This possibly occurred because of the association between alcohol abuse and number of partners greater than or equal to four $\left(\mathrm{chi}^{2}=8.82 ; \mathrm{p}=0.012\right)$, which was also associated with HPV infection, thus suggesting that alcohol abuse may have been a confounding variable in our study. As there is no biological plausibility for alcoholism to be considered a protective factor for acquiring HPV infection, we believe that there may have been an information bias at the time of application of the questionnaire or perhaps alcoholism expresses another variable that was not considered in the study. Alcohol abuse was not shown to be associated with cervical infection due to HPV among HIV-positive (Melgaço et al. 2011) and HIV-negative women in southeastern Brazil (Augusto et al. 2014).

The association between smoking and cervical cancer among HIV-positive patients has been described (Fonseca-Moutinho 2011, Naucler et al. 2011). However, smoking does not appear to be involved in the acquisition of HPV infection, even though its role in the pathogenesis of the development of cervical cancer is known (Frega et al. 2006). We found no association between smoking and HPV infection in HIV-positive women, perhaps because our study population had a low prevalence of CIN (4.6\%) and cervical cancer $(0.14 \%)$.

We did not observe an association between pregnancy and HPV infection in the HIV-infected patients 
$(\mathrm{p}=0.357)$, but others have reported such an association (Meyrelles 2013).

There remains a controversy regarding the relationship between HPV infection and education level. In our study, the HIV-positive women with a higher educational level, i.e., with at least eight years of schooling, presented twice as much a chance of having HPV infection. However, other Brazilian studies have shown a lack of relationship between HPV infection among HIV-positive women and their educational level (Grinsztejn et al. 2009, Melgaço et al. 2011, Araújo et al. 2012).

Within this context, we analysed the adherence of the HIV-positive women to the Brazilian Ministry of Health's cervical cancer prevention programme according to their educational level and found an association among these women between a higher educational level and not undergoing the Papanicolaou test $\left(\mathrm{chi}^{2}=4.43 ; \mathrm{p}\right.$ $=0.035$ ). In addition, the women who underwent the test did so at intervals greater than one year $\left(\mathrm{chi}^{2}=6.45 ; \mathrm{p}\right.$ $=0.011$ ). These findings may suggest that these women have a lower level of care.

Evolution of HPV infection among HIV-positive women - Among the 196 HIV-positive women who were followed up for four years, we found a low level of persistence of HPV (13.4\%) in relation to the persistence of HPV infection among HIV-negative women reported in studies conducted in Germany (56\%), the Netherlands (44\%) and Africa (32\%) (Melsheimer et al. 2001, Veldhuijzen et al. 2011, Schmeink et al. 2011). One of the explanations for this is the lower prevalence of cervical lesions in our patients (13.9\%), which may have been due to their better immunological state, given that $80 \%$ of the women presented $\mathrm{CD}^{+} \mathrm{T}$ lymphocyte counts greater than 200 cells $/ \mathrm{mm}^{3}$, independent of the presence of HPV co-infection. This observation corroborates another study in southeastern Brazil that showed a similar HPV prevalence $(46.6 \%)$ and also a low frequency of cervical lesions (7.3\%) among 178 HIV-positive women using highly active anti-retroviral therapy; the authors reported that more than $60 \%$ of the patients had $\mathrm{CD}^{+} \mathrm{T}$ lymphocyte counts higher than 200 cells $/ \mathrm{mm}^{3}$ (RochaBrischiliari et al. 2014)

Considering only infection with a high risk HPV, a Dutch study with HIV-negative women showed that the chance of HPV persistence depends on the type and on the duration of the infection. The type-specific infection identified since baseline or at month 6 had a greater chance of persisting in the second study year compared to newly detected infections at month 12 (Schmeink et al. 2011).

A CD4 ${ }^{+}$T lymphocyte count greater than $200 / \mathrm{mm}^{3}$ is a factor associated with the regression of HPV infection among HIV-positive women, both for high-risk and for low-risk HPV (Louvanto et al. 2010, Kravchenko et al. 2012). Considering the presence of HPV in the cervical samples taken during follow-ups of our patients, the regression rate measured in terms of negative tests was $65.8 \%$ of the cases that had been positive in the first evaluation. However, the progression rate, i.e., the presence of HPV in the last sample evaluated from women who initially were negative, was only $28.3 \%$. Once again, this reflects the patients' good immunological status. It also reflects the quality of treatment provided through the Brazilian National Health System, which offers medications free of charge for all HIV-positive patients, clinical follow-up with $\mathrm{CD} 4^{+} \mathrm{T}$ lymphocyte counts and annual cervical cytological examinations.

One limitation in our study was the loss of followup data due to the long period of observation. We partially overcame this problem by conducting a recall of all volunteer women by telephone after a six-month interval from the first consult for clinical and laboratory re-evaluation and we were able to follow up with 219 women ( $48.7 \%$ of all). In addition, the low prevalence of women with severe cervical lesions did not enable us to fully evaluate the association of risk factors with cervical cancer susceptibility, though more information was produced on the effect of proper anti-HIV therapy and $\mathrm{CD} 4^{+}$counting in HPV infection and cervical lesion regression. The presence of inhibitors in bloody cervical samples was initially a limitation, but we performed DNA purification on those samples prior to PCR amplification and the sample loss represented less than $2.5 \%$ of the study population (11 of 461). We were also not able to type 36 of the 214 viral isolates, representing a loss of $17 \%$ cases; furthermore, it was not possible to identify them using the PCR-RFLP strategy, suggesting an infection by multiple virus types.

In conclusion, the low prevalence of HPV-16 infection in the HIV-positive women with normal cytology and a better immune status might explain the low incidence of severe cervical lesions. Recent studies showed that the prevalence of HPV-16 ranged from 13.9-49.4\% in our region (Brandão et al. 2009, Baldez et al. 2012). For these studies, HIV-negative women with prior HPV infection or HIV-positive pregnant women were selected and the difference between the groups precluded a direct comparison with our study. The importance of regional variability of HPV subtypes for policies toward the development of vaccines against HPV infection and cervical cancer should be a motive for future studies. It is important to know whether the range of regional variability of HPV subtypes found among HIV-positive women is a reality for the population of HIV-negative women. Despite the favourable scenario presented in this study, there is a need to clarify the effect of cervical infection due to subtypes other than HPV 16 in relation to persistence of the disease and the occurrence of CIN in HIV-positive patients. New follow-up studies with a greater number of women and less information loss may help toward a better understanding of HPV-HIV coinfection, the causes of persistence of HPV infection and infection outcomes among HIV-positive patients.

\section{ACKNOWLEDGEMENTS}

To Viviane Carvalho, for technical assistance, to the PDTIS-Fiocruz, to Vicente Marconi Amorim de Oliveira, LACEN-PE, for the data on lymphocytes $\mathrm{T} \mathrm{CD} 4^{+}$counting, and to Dr François Figueirôa and Khaled Almahnoud, SES$\mathrm{PE}$, for the data on ART use. 


\section{REFERENCES}

Araújo AC, Carvalho NO, Teixeira NC, Souza TT, Murta ED, Faria IM, Corrêa CM, Lima MI, Del Castillo DM, Melo VH 2012. Incidence of cervical intraepithelial neoplasia in a cohort of HIVinfected women. Int J Gynaecol Obstet 117: 211-216.

Augusto EF, Santos LS, Oliveira LH 2014. Human papillomavirus detection in cervical scrapes from women attended in the Family Health Program. Rev Lat Am Enfermagem 22: 100-107.

Baldez da Silva MF, Guimarães V, Silva MA, Medeiros do Amaral CM, Beçak W, Stocco RC, Freitas AC, Crovella S 2012. Frequency of human papillomavirus types 16, 18, 31 and 33 and sites of cervical lesions in gynecological patients from Recife, Brazil. Genet Mol Res 11: 462-466.

Bhatla N, Puri K, Joseph E, Kriplani A, Iyer VK, Sreenivas V 2013. Association of Chlamydia trachomatis infection with human papillomavirus (HPV) and cervical intraepithelial neoplasia - a pilot study. Indian J Med Res 137: 533-539.

Bicca GLO, da Silveira MF, Silva SM, da Silva KRS, de Barros FCLF 2013. Prevalence of infection with high-risk HPV in women using hybrid capture conducting prevention of certvical cancer in southern Brazil. J bras Doenças Sex Transm 25: 109-114.

Brandão VCRAB, Lacerda HR, Lucena-Silva N, Ximenes RAA 2009. Frequency and types of human papillomavirus among pregnant and non-pregnant women with human immunodeficiency virus infection in Recife determined by genotyping. Mem Inst Oswaldo Cruz 104: 755-763.

Burk RD, Ho GY, Beardsley L, Lempa M, Peters M, Bierman R 1996. Sexual behavior and partner characteristics are the predominant risk factors for genital human papillomavirus infection in young women. J Infect Dis 174: 679-689.

Clifford GM, Rana RK, Franceschi S, Smith JS, Gough G, Pimenta JM 2005. Human papillomavirus genotype distribution in low-grade cervical lesions: comparison by geographic region and with cervical cancer. Cancer Epidemiol Biomarkers Prev 14: 1157-1164.

Confortini M, Carozzi F, Zappa M, Ventura L, Iossa A, Cariaggi P, Brandigi L, Franchini M, Mirri F, Viacava P, Scarfantoni A, Bazzanti D, Sani 2010. Human papillomavirus infection and risk factors in a cohort of Tuscan women aged 18-24: results at recruitment. BMC Infect Dis 10: 157.

Corrêa CM, Teixeira NC, Araújo AC, Carvalho NO, Castillo DM, Campos RR, Oliveira IV, Alves AR, França AF, Melo VH 2011. Prevalence and multiplicity of HPV in HIV women in Minas Gerais, Brazil. Rev Assoc Med Bras 57: 425-430.

de Villiers EM, Fauquet C, Broker TR, Bernard HU, zur Hausen H 2004. Classification of papillomaviruses. Virology 324: 17-27.

Entiauspe LG, Teixeira LO, Mendoza-Sassi RA, Gonçalves CV, Gonçalves P, Martinez AM 2010. Human papillomavirus: prevalence and genotypes found among HIV-positive and negative women at a reference center in the far south of Brazil. Rev Soc Bras Med Trop 43: 260-263.

Fonseca-Moutinho JA 2011. Smoking and cervical cancer. Obstet Gynecol 2011: 1-6.

Frega A, Biamonti A, Maranghi L, Vetrano G, Palazzo A, Iacovelli R, Corosu R, French D, Moscarini M, Vecchione A 2006. Follow-up of high-grade squamous intra-epithelial lesions (H-SIls) in human immunodeficiency virus (HIV)-positive and human papillomavirus (HPV)-positive women. Analysis of risk factors. Anticancer Res 26: 3167-3170.

Garbuglia AR, Piselli P, Lapa D, Sias C, Del Nonno F 2012. Frequency and multiplicity of human papillomavirus infection in HIV-1 positive women in Italy. J Clin Virol 54: 141-146.
Gillet E, Meys JF, Verstraelen H, Verhelst R, De Sutter P, Temmerman M, Vanden Broeck D 2012. Association between bacterial vaginosis and cervical intraepithelial neoplasia: systematic review and meta-analysis. PLoS ONE 7: e45201.

Giuliano AR, Papenfuss M, Schneider A, Nour M, Hatch K 1999. Risk factors for high-risk type human papillomavirus infection among Mexican-American women. Cancer Epidemiol Biomarkers Prev 8: 615-620.

Grinsztejn B, Veloso VG, Levi JE, Velasque L, Luz PM, Friedman RK, Andrade AC, Moreira RI, Russomano F, Pilotto JH, Bastos FI, Palefsky J 2009. Factors associated with increased prevalence of human papillomavirus infection in a cohort of HIV-infected Brazilian women. Int J Infect Dis 13: 72-80.

Hariri S, Unger ER, Sternberg M, Dunne EF, Swan D, Patel S, Markowitz LE 2011. Prevalence of genital human papillomavirus among females in the United States, the National Health And Nutrition Examination Survey, 2003-2006. J Infect Dis 204: 566-573.

INCA - Instituto Nacional de Câncer 2011. Diretrizes brasileiras para o rastreamento do câncer do colo do útero. Available from: inca.gov.br.

Kravchenko J, Akushevich I, Sudenga SL, Wilson CM, Levitan EB, Shrestha S 2012. Transitional probability-based model for HPV clearance in HIV-1-positive adolescent females. PLoS ONE 7: e30736.

Landis JR, Koch GG 1977. The measurement of observer agreement for categorical data. Biometrics 33: 159-174.

Louvanto K, Syrjänen KJ, Rintala MA, Grénman SE, Syrjänen SM 2010. Genotype-specific clearance of genital human papillomavirus (HPV) infections among mothers in the Finnish family HPV study. J Clin Microbiol 48: 2665-2671.

Luque AE, Jabeen M, Messing S, Lane CA, Demeter LM, Rose RC, Reichman RC 2006. Prevalence of human papillomavirus genotypes and related abnormalities of cervical cytological results among HIV-1-infected women in Rochester, New York. $J$ Infect Dis 194: 428-434.

Luz PM, Velasque L, Friedman RK, Russomano F, Andrade AC, Moreira RI, Chicarino-Coelho J, Pires E, Veloso VG, Grinsztejn B 2012. Cervical cytological abnormalities and factors associated with high-grade squamous intraepithelial lesions among HIV-infected women from Rio de Janeiro, Brazil. Int J STD AIDS 23: 12-17.

Macleod IJ, O’Donnell B, Moyo S, Lockman S, Shapiro RL, Kayembe M, van Widenfelt E, Makhema J, Essex M, Wester C 2011. Prevalence of human papillomavirus genotypes and associated cervical squamous intraepithelial lesions in HIV-infected women in Botswana. J Med Virol 83: 1689-1695.

Manos MM, Ting Y, Wright DK, Lewis AJ, Broker TR 1989. Use of polymerase chain reaction amplification for the detection of genital human papillomaviruses. Cancer Cells 7: 209-214.

Martín P, Kilany L, García D, López-García AM, Martín-Azaña MJ, Abraira V, Bellas C 2011. Human papillomavirus genotype distribution in Madrid and correlation with cytological data. BMC Infect Dis 11: 316.

Melgaço FG, Rosa ML, Augusto EF, Haimuri JG, Jacintho C, Santos LS, Cavalcanti SM, Oliveira LH 2011. Human papillomavirus genotypes distribution in cervical samples from women living with human immunodeficiency virus. Arch Gynecol Obstet 283: 809-817.

Melsheimer P, Klaes R, von Knebel Doeberitz M, Bastert G 2001. Prospective clinical study comparing DNA flow cytometry and HPV typing as predictive tests for persistence and progression of CIN I/II. Cytometry 46: 166-171.

Meyrelles ARI 2013. Prevalence, genotypes of human papillomavirus infection and risk factors for persistence in a cohort of HIV-infected pregnant women. J bras Doenças Sex Transm 25: 115. 
Naucler P, Mabota da Costa F, da Costa JL, Ljungberg O, Bugalho A, Dillner J 2011. Human papillomavirus type-specific risk of cervical cancer in a population with high human immunodeficiency virus prevalence: case-control study. J Gen Virol 92: 2784-2791.

Nicol AF, Grinsztejn B, Friedman RK, Veloso VG, Cunha CB, Georg I, Pilotto JH, Moreira RI, Castro CA, Silver B, Viscidi RP 2013. Seroprevalence of HPV vaccine types 6,11,16 and 18 in HIV-infected and uninfected women from Brazil. J Clin Virol 57: 147-151.

Palefsky 2006. Biology of HPV in HIV infection. Adv Dent Res 19: 99-105.

Rahman M, Sasagawa T, Yamada R, Kingoro A, Ichimura H, Makinoda S 2011. High prevalence of intermediate-risk human papillomavirus infection in uterine cervices of Kenyan women infected with human immunodeficiency virus. J Med Virol 83: 1988-1996.

Rocha-Brischiliari SC, Gimenes F, de Abreu AL, Irie MM 2014. Risk factors for cervical HPV infection and genotypes distribution in HIV-infected south Brazilian women. Infect Agent Cancer 9: 6.

Rodriguez-Cerdeira C, Sanchez-Blanco E, Alba A 2012. Evaluation of association between vaginal infections and high-risk human papillomavirus types in female sex workers in Spain. Obstet $G y$ necol 2012: e240190.

SBPTGIC - Sociedade Brasileira de Patologia do Trato Genital Inferior e Colposcopia 2003. Terminologia colposcópica. Bol Inf Dir SBPTGIC 5: 5-6.

Schmeink CE, Melchers WJG, Siebers AG, Quint WGV, Massuger LFAG, Bekkers RL 2011. Human papillomavirus persistence in young unscreened women, a prospective cohort study. PLOS ONE 6: e27937.
Schneider ML, Schneider V 1998. Atlas de diagnóstico diferencial em citologia ginecológica, Revinter, Rio de Janeiro, 165 pp.

Tamura K, Peterson D, Peterson N, Stecher G, Nei M, Kumar S 2011. MEGA5: molecular evolutionary genetics analysis using maximum likelihood, evolutionary distance and maximum parsimony methods. Mol Biol Evol 28: 2731-2739.

Veldhuijzen NJ, Braunstein SL, Vyankandondera J, Ingabire C, Ntirushwa J, Kestelyn E, Tuijn C, Wit FW, Umutoni A, Uwineza M, Crucitti T, van de Wijgert JH 2011. The epidemiology of human papillomavirus infection in HIV-positive and HIV-negative highrisk women in Kigali, Rwanda. BMC Infect Dis 11: 333.

Videla S, Darwich L, Cañadas MP, Paredes R, Tarrats A, Castella E, Llatjos M, Bofill M, Clotet B, Sirera G 2009. Epidemiological data of different human papillomavirus genotypes in cervical specimens of HIV-1-infected women without history of cervical pathology. J Acquir Immune Defic Syndr 50: 168-175.

Walboomers JM, Jacobs MV, Manos MM, Bosch FX, Kummer JA, Shah KV, Snijders PJ, Peto J, Meijer CJ, Muñoz N 1999. Human papillomavirus is a necessary cause of invasive cervical cancer worldwide. J Pathol 189: 12-19.

Watts DH, Fazzari M, Minkoff H, Hillier SL, Sha B, Glesby M, Levine AM, Burk R, Palefsky JM, Moxley M, Ahdieh-Grant L, Strickler HD 2005. Effects of bacterial vaginosis and other genital infections on the natural history of human papillomavirus infection in HIV-1-infected and high-risk HIV-1-uninfected women. J Infect Dis 191: 1129-1139.

Yamada R, Sasagawa T, Kirumbi LW, Kingoro A, Karanja DK, Kiptoo M, Nakitare GW, Ichimura H, Inoue M 2008. Human papillomavirus infection and cervical abnormalities in Nairobi, Kenya, an area with a high prevalence of human immunodeficiency virus infection. J Med Virol 80: 847-855. 